\title{
Pengaruh Kehalusan Pasir terhadap Kuat Tekan Beton
}

\author{
Boedi Wibowo $^{1)}$, Endang Kasiati ${ }^{1)}$, Triaswati ${ }^{1)}$, Dewi Pertiwi ${ }^{2)}$ \\ 1) Program Studi Diploma Teknik Sipil FTSP ITS, Surabaya \\ 2) Jurusan Teknik Sipil ITATS, Surabaya \\ Email: en_kas@ce.its.ac.id
}

\begin{abstract}
Concrete compressive strength depend on many factors, one of the critical factor is fineness of sand, one material component of concrete. This study aims to quantify effect of the sand fineness to the concrete compressive strength by using sand with zone I and zone III. Water-cement ratio (W/C) is varied at 0,3; 0,5 and 0,6. For all tests sample, $20 \%$ fly ash is added. Compressive strength design is set at $300 \mathrm{~kg} / \mathrm{cm}^{2}$ and cylinder sample with diameter of $15 \mathrm{~cm}$ and height of $30 \mathrm{~cm}$ is used. Compressive strength of the concrete sample at 28 days curing shows the following results. For samples with W/C of 0,6, compressive strength of the samples is below $300 \mathrm{~kg} / \mathrm{cm}^{2}$. For samples with W/C of 0,5, compressive strength of the samples using sand with zone I and zone III are 402,57 $\mathrm{kg} / \mathrm{cm}^{2}$ and $351,56 \mathrm{~kg} / \mathrm{cm}^{2}$, respectively. For samples with W/C of 0,3 , compressive strength of the samples using sand with zone I and zone III are $560,476 \mathrm{~kg} / \mathrm{cm}^{2}$ and $663,83 \mathrm{~kg} / \mathrm{cm}^{2}$, respectively.
\end{abstract}

Keywords: fineness of sand, water-cement ratio, Concrete compressive strength.

\section{Abstrak}

Salah satu faktor yang mempengaruhi kuat tekan beton adalah kehalusan material pasir yang digunakan dalam campuran beton. Penelitian ini ditujukan untuk mengukur perbedaan kuat tekan beton akibat pengunaan bahan pasir zone I dan Zone III. Faktor Air Semen (FAS) divariasi sebesar 0,3, 0,5, dan 0,6 serta campuran fly ash ditetapkan sebesar $20 \%$ untuk semua sampel. Kuat tekan rencana ditetapkan sebesar $300 \mathrm{~kg} / \mathrm{cm}^{2}$ dengan benda uji berbentuk silinder yang memiliki diameter $15 \mathrm{~cm}$ dan tinggi $30 \mathrm{~cm}$. Hasil pengujian kuat tekan sampel pada umur 28 hari adalah sebagai berikut: Untuk FAS 0,6, sampel dengan campuran pasir zone I dan zone III menghasilkan kuat tekan lebih kecil dari $300 \mathrm{~kg} / \mathrm{cm}^{2}$. Untuk FAS 0,5, sampel dengan campuran pasir zone I menghasilkan kuat tekan $402,57 \mathrm{~kg} / \mathrm{cm}^{2}$ dan zone III menghasilkan kuat tekan $351,56 \mathrm{~kg} / \mathrm{cm}^{2}$. Sedangkan untuk FAS 0,3, sampel dengan campuran pasir zone I menghasilkan kuat tekan $560,476 \mathrm{~kg} / \mathrm{cm}^{2}$ dan zone III menghasilkan kuat tekan $663,83 \mathrm{~kg} / \mathrm{cm}^{2}$.

Kata kunci: kehalusan pasir, faktor air semen, kuat tekan beton.

\section{Pendahuluan}

Dalam menghadapi era globalisasi dunia, Indonesia yang dikenal sebagai salah satu negara berkembang dituntut untuk lebih kreatif serta memiliki keterampilan yang mencukupi dalam penelitian dan pengembangan bidang konstruksi, terutama pada teknologi pembuatan beton (Subakti, 1995).

Berbagai cara untuk mencari material alternatif untuk pembuatan beton terus dilakukan. Salah satunya dengan men- cari kehalusan pasir yang efisien dan memiliki kuat tekan yang optimum. Dimana dalam penelitian ini menggunakan dua modulus kehalusan pasir asal Lumajang yang memiliki besar butiran yang berbeda yaitu pasir pada zone I dan pasir pada zone III.

Pasir zone I yang digunakan dalam penelitian ini berasal dari kota Lumajang, didapatkan dengan cara penambangan. Pasir halus memiliki kualitas yang tak kalah bagus jika dibandingkan 
dengan pasir sungai yang umum digunakan dalam pembuatan beton. Pasir zone I memiliki butiran yang seperti kristal. Sementara itu, pasir zone III didapatkan dari hasil penambangan di Lumajang. Pasir ini memiliki butiran yang lebih hitam dan kasar.

Untuk itulah, dalam penelitian ini di usahakan untuk mencari "Perbandingan Modulus Kehalusan Pasir Ditinjau Dari Kuat Tekan Beton", dengan memanfaatkan campuran dua jenis agregat halus itu dalam pembuatan beton. Dimana, pemanfaatannya diharapkan bisa meningkatkan nilai kuat tekan beton tersebut.

Untuk perhitungan beton pada umur 28 hari, menggunakan perhitungan sebagai berikut:

Kuat Tekan Individu:

$f c i=\frac{P}{A}$.

Kuat Tekan Rata-rata (Subakti, 1995):

$f c r=\sum_{i=1}^{n} f c i+n$

Kuat Tekan Karakteristik:

$f c^{\prime}=f c r-(1,64 \times s)$.

dimana:

$\mathrm{P}=$ Beban maksimum $(\mathrm{kg})$

$\mathrm{A}=$ Luas penampang benda uji $\left(\mathrm{cm}^{2}\right)$

$\mathrm{S}=$ Deviasi standar $\left(\mathrm{kg} / \mathrm{cm}^{2}\right)$

$\mathrm{f}_{\mathrm{ci}}=$ Kuat tekan beton yang didapat dari hasil pengujian $\left(\mathrm{kg} / \mathrm{cm}^{2}\right)$

$\mathrm{f}_{\mathrm{cr}}=$ Kuat tekan beton rata-rata $\left(\mathrm{kg} / \mathrm{cm}^{2}\right)$

$\mathrm{n}=$ Jumlah benda uji, minimum 20 buah

\section{Metodologi}

Pada penelitian ini, metode pembuatan dan pengujian menggunakan sejumlah benda uji beton silinder $(\varnothing 15 \mathrm{~cm}$, tinggi $30 \mathrm{~cm}$ ) (Wangsadinata, 1979) dengan kuat tekan hancur rencana 30 Mpa. Benda uji tersebut terdapat di laboratorium Jaminan Mutu dan Inovasi (JMI) PT. Varia Usaha Beton. Jumlah total benda uji tersebut sebanyak 180 buah (terdapat 6 varian dan tiap varian terdiri dari 30 benda uji) dengan perpaduan komposisi pasir silika dan pasir limbah 0\%, 25\%, 50\%, 75\%, $100 \%$, menggunakan variasi faktor air semen (FAS) 0,6; 0,5; dan 0,3, dan dicampurkan dengan fly ash sebesar $20 \%$. Benda uji tersebut, kemudian diuji kuat tekan pada umur 7, 14, dan 28 hari untuk mencari varian yang memiliki kuat tekan paling optimum. Bahan yang harus disediakan (Murdock, 1986) adalah:

- Semen tipe I

- Air

- Pasir zone I (Gambar 1)

- Pasir zone III (Gambar 2)

- Batu pecah

- Fly ash

Data perancangan yang akan dipakai dalam pembuatan benda uji adalah sebagai berikut:

a. Kuat tekan hancur yang direncanakan $30 \mathrm{MPa}$.

b. Deviasi standar $35 \mathrm{~kg} / \mathrm{cm}^{2}$

c. Jenis Semen Semen Portland tipe I.

d. Jenis Agregat Kasar Batu Pecah

e. Jenis Agregat Halus Pasir zone I dan Pasir zone III.

f. Slump 10-30 mm. 


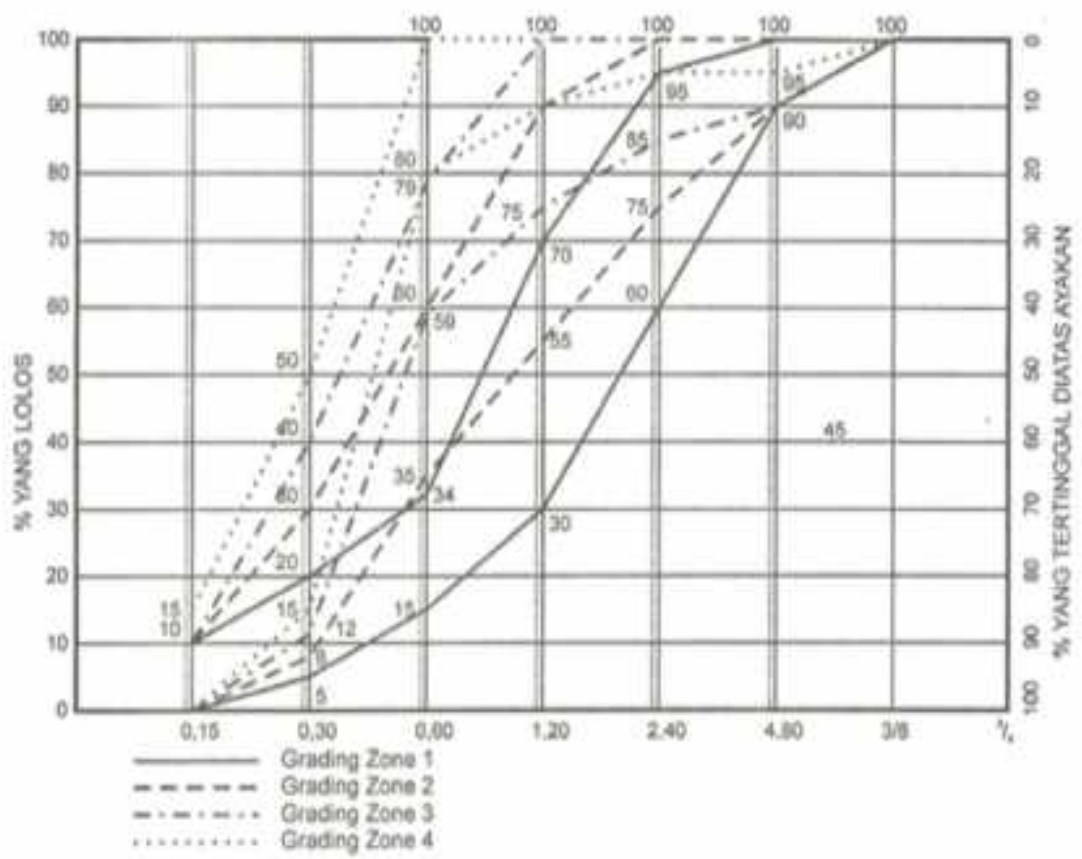

Gambar 1. Analisa ayakan Pasir Zone I

Pembuatan benda uji dilakukan sesuai SNI-03-2847-2002; SII 0052-80; SII 0287-80; SII 0013-77, dengan ketentuan antara lain:

a. Cetakan untuk benda uji harus presisi ukurannya dan juga tertutup rapat sehingga tidak memungkinkan air beton keluar dari cetakan.

b. Memposisikan benda uji yang telah ditimbang ke dalam mesin uji tekan setepat mungkin agar pembebanan tepat ditengah benda uji agar mendapatkan hasil yang tepat.

c. Agar hasil lebih bagus permukaan beton yang akan diuji harus di capping terlebih dahulu agar permukaannya lebih datar.

d. Pengadukan campuran beton memakai mesin pengaduk (molen) untuk mempermudah dan mempercepat pekerjaan.

e. Pemadatan beton juga dilakukan dengan penggetaran di atas mesin peng- getar selama \pm 3 menit atau dengan menggunakan palu karet untuk memukul cetakan beton.

f. Perawatan beton dengan perendaman selama 28 hari di dalam air bersih.

\section{Hasil dan Pembahasan}

- Pasir Zone I

a.Syarat Kebersihan

- Kadar Lumpur : 1,4 \%

b. Modulus Kehalusan :-

c. Berat Volume
- Lepas
$: 1,66 \mathrm{gr} / \mathrm{m} 3$
- Rojok
$: 1,67 \mathrm{gr} / \mathrm{m}^{3}$
d. Kelembaban
: $2,8 \%$
e. Berat Jenis (SSD) : 2,6
f. Kekerasan
$: \quad-$
g. Resapan
$: 2,8$
h. Grading Zone
: Zone I

- Pasir Zone III

a. Syarat Kebersihan

- Kadar Lumpur : 3,8 \%

b. Modulus Kehalusan :- 


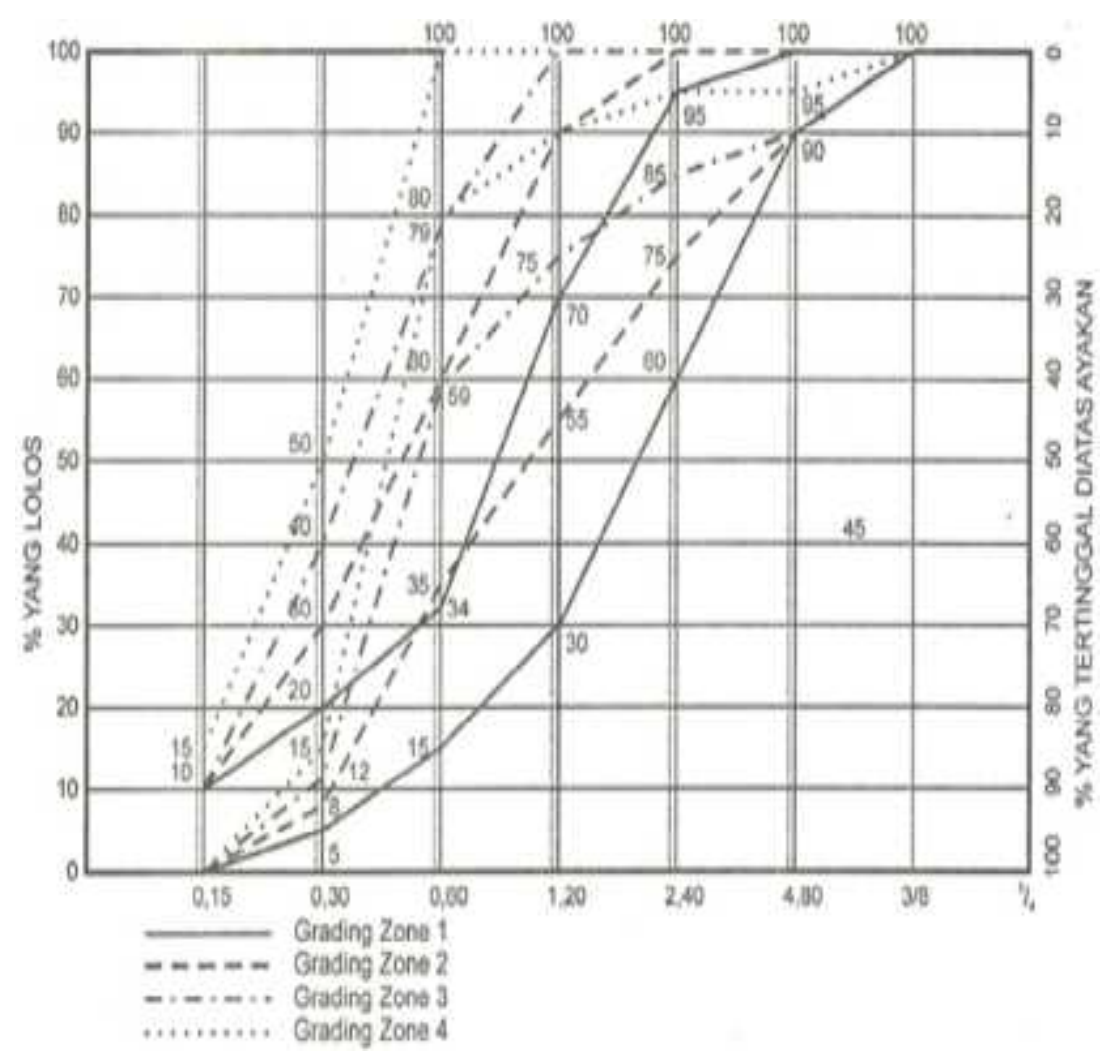

Gambar 2. Analisa ayakan Pasir Zone III

c. Berat Volume

- Lepas

- Rojok

d. Kelembaban

e. Berat Jenis (SSD) : 2,4

f. Kekerasan

g. Resapan $: 2,2$

h. Grading Zone

: Zona III

- Batu Pecah

a. Syarat Kebersihan

- Kadar Organis

b. Kadar Lumpur $\quad: 1,4150 \%$

c. Modulus Kehalusan : 2,49

d. Berat Volume

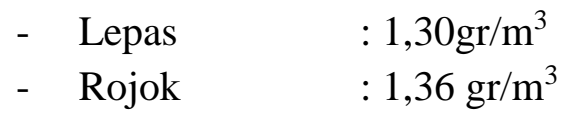

e. Kelembaban : $1,29 \%$

f. Berat Jenis (SSD) : 2,71

g. Kekerasan h. Resapan

$: 1,95 \%$

Hasil percobaan berat jenis agregat kasar memenuhi persyaratan agregat beton yang telah ditentukan ASTM, yaitu dalam kisaran nilai 1,60-3,20. Hasil percobaan air resapan agregat kasar memenuhi persyaratan yang telah ditentukan ASTM C 127-88 Reapp. 93, maksimal 4,0\% untuk agregat campuran beton. Hasil percobaan berat volume agregat kasar memenuhi persyaratan yang telah ditentukan ASTM C29/C29 M-91 A, yaitu dalam kondisi lepas memenuhi spesifikasi $0,4-1,9 \mathrm{~kg} / \mathrm{lt}$ dan pada kondisi padat (rojok) memenuhi spesifikasi 0,4-1,9 kg/lt. Hasil percobaan kelembaban agregat kasar memenuhi persyaratan yang telah ditentukan 
ASTM C 556-89, yaitu sebesar 0,5\%$2,0 \%$ untuk agregat campuran beton.

Ketentuan Mix Design adalah sebagai berikut:

1. Kuat tekan hancur yang direncanakan

: $30 \mathrm{MPa}$

2. Deviasi standar $: 35 \mathrm{~kg} / \mathrm{cm}^{2}$

3. Jenis Semen : Semen Portland tipe I

4. Jenis Agregat Kasar: Batu Pecah

5. Jenis Agregat Halus: Pasir Lumajang

6. Faktor Air Semen : 0,30 0,50 0,60

7. Fly ash $: 20 \%$

8. Slump

: $10-30$ $\mathrm{mm} / 80-100$

9. Umur perawatan : 7,14 , dan 28 hari

10. Jenis benda uji

: Silinder dengan $\varnothing 15$ $\mathrm{cm}$, tinggi 30 $\mathrm{cm}$

Nilai hasil pengujian tes kuat tekan beton berdasarkan FAS 0,6 pada umur 7,14, dan 28 hari terlihat pada gambar 3 .

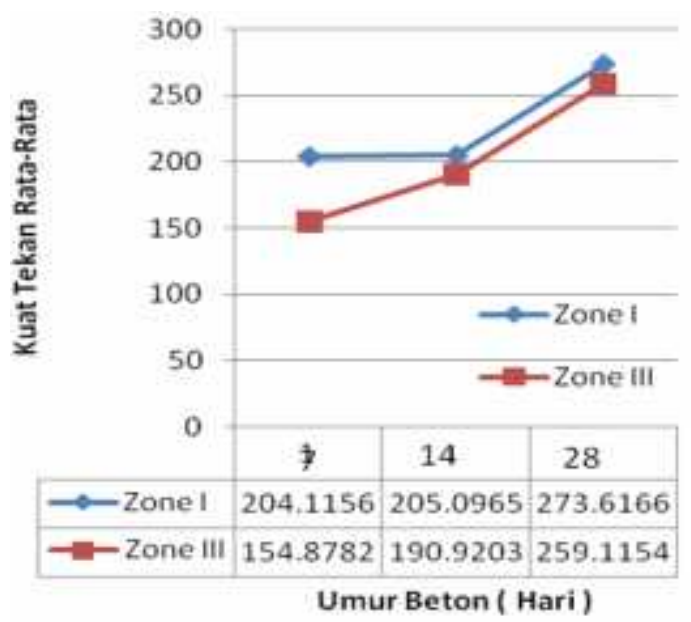

Gambar 3. Grafik kuat tekan FAS 0,6 dalam varian umur
Varian butiran pasir zone I pada umur 7 hari kuat tekannya 204,12 kg/cm ${ }^{2}$, pada umur 14 hari kuat tekannya naik menjadi $205,10 \mathrm{~kg} / \mathrm{cm}^{2}$ dan pada umur 28 hari mengalami kenaikan sebesar $273,62 \mathrm{~kg} / \mathrm{cm}^{2}$. Varian butiran pasir zone III pada umur 7 hari kuat tekannya $154,88 \mathrm{~kg} / \mathrm{cm}^{2}$, pada umur 14 hari kuat tekannya naik menjadi $190,92 \mathrm{~kg} / \mathrm{cm}^{2}$ dan pada umur 28 hari mengalami kenaikan sebesar $259,12 \mathrm{~kg} / \mathrm{cm}^{2}$.

Maka varian pasir zone I memiliki kuat optimum yang lebih dibandingkan butiran pasir zone III yaitu 273,62 $\mathrm{kg} / \mathrm{cm}^{2}$. Tapi belum memenuhi syarat kuat tekan (fc') yang direncanakan, sebesar $300 \mathrm{~kg} / \mathrm{cm}^{2}$.

Nilai hasil pengujian tes kuat tekan beton berdasarkan FAS 0,5 pada umur 7,14, dan 28 hari terlihat pada gambar 4.

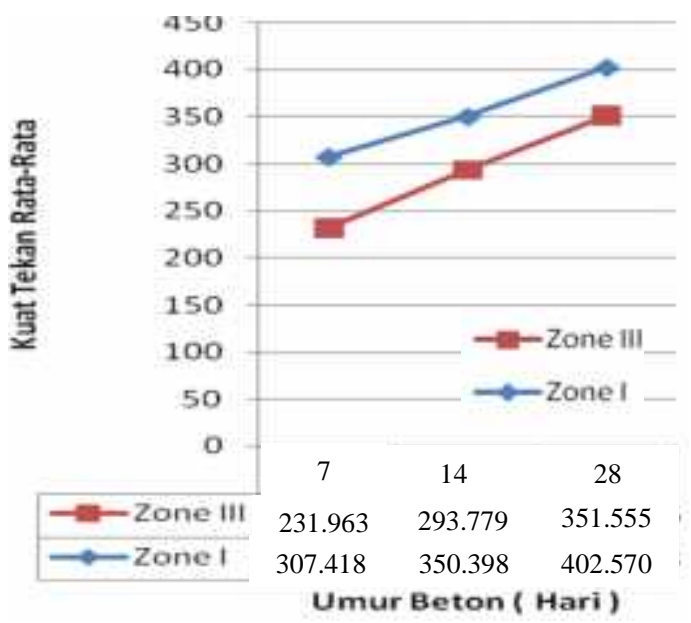

Gambar 4. Grafik kuat tekan FAS 0,5 dalam varian umur

Varian butiran pasir zone III pada umur 7 hari kuat tekannya $231,96 \mathrm{~kg} / \mathrm{cm}^{2}$, pada umur 14 hari kuat tekannya naik menjadi $293,78 \mathrm{~kg} / \mathrm{cm}^{2}$ dan pada umur 28 hari mengalami kenaikan sebesar $351,56 \mathrm{~kg} / \mathrm{cm}^{2}$. Varian butiran pasir zone I pada umur 7 hari kuat tekannya 
$307,42 \mathrm{~kg} / \mathrm{cm}^{2}$, pada umur 14 hari kuat tekannya naik menjadi $350,40 \mathrm{~kg} / \mathrm{cm}^{2}$ dan pada umur 28 hari mengalami kenaikan sebesar 402,57 kg/ $\mathrm{cm}^{2}$.

Maka varian pasir zone I memiliki kuat optimum yang lebih dibandingkan butiran pasir zone III yaitu $402,57 \mathrm{~kg} / \mathrm{cm}^{2}$. Dan telah memenuhi syarat kuat tekan (fc') yang direncanakan, sebesar 300 $\mathrm{kg} / \mathrm{cm}^{2}$.

Pada gambar 5 adalah nilai hasil pengujian tes kuat tekan beton berdasarkan FAS 0,3 pada umur 7, 14, dan 28 hari.

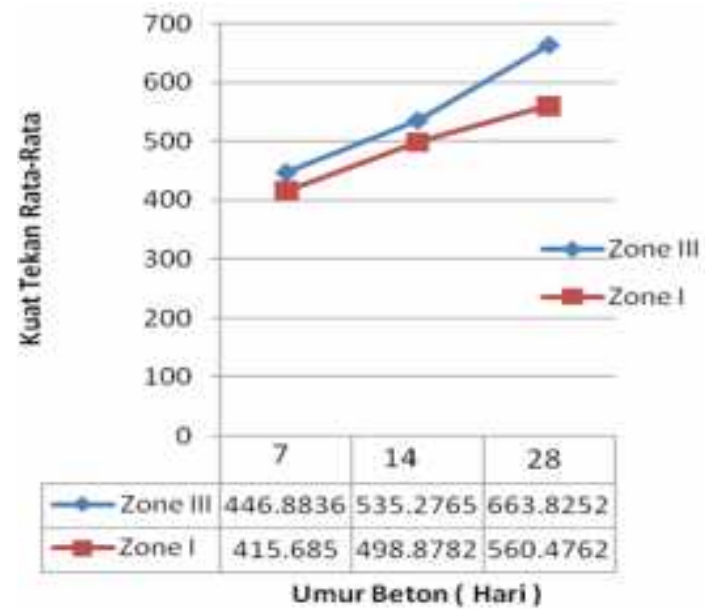

Gambar 5. Grafik kuat tekan FAS 0,3 dalam varian umur

Varian butiran pasir zone I pada umur 7 hari kuat tekannya $446,88 \mathrm{~kg} / \mathrm{cm}^{2}$, pada umur 14 hari kuat tekannya naik menjadi $535,28 \mathrm{~kg} / \mathrm{cm}^{2}$ dan pada umur 28 hari mengalami kenaikan sebesar $663,83 \mathrm{~kg} / \mathrm{cm}^{2}$. Varian butiran pasir zone III pada umur 7 hari kuat tekannya $415,69 \mathrm{~kg} / \mathrm{cm}^{2}$, pada umur 14 hari kuat tekannya naik menjadi $498,88 \mathrm{~kg} / \mathrm{cm}^{2}$ dan pada umur 28 hari mengalami kenaikan sebesar 560,48 kg/ $\mathrm{cm}^{2}$.

Maka varian pasir zone III memiliki kuat tekan optimum yang lebih besar dibandingkan butiran pasir zone I yaitu $663,83 \mathrm{~kg} / \mathrm{cm}^{2}$. Dan telah memenuhi syarat kuat tekan (fc') yang direncanakan, sebesar $300 \mathrm{~kg} / \mathrm{cm}^{2}$.

Kuat tekan yang tinggi dimungkinkan karena ikatan/lekatan antara semen dan agregat yang dapat menyelimuti semua agregat dan juga dipengaruhi adanya aktifitas pozzolan dari fly ash sehingga semakin lama umur beton maka kesempurnaan proses hidrasi semennya dapat dicapai. Hal ini ditambah juga dengan menggunakan FAS 0,3 karena semakin kecil nilai FAS, maka semakin besar pula kekuatannya.

\subsection{Uji statistik Anova Satu Arah}

Dari data kuat tekan beton hasil konversi, beton pasir Zone I dengan beton pasir Zone III, diambil data untuk di masukkan ke dalam uji Anova satu arah, yang kemudian didapat hasil seperti pada tabel 1 .

Berdasarkan output tabel 1 dan 2, Ho ditolak karena $\mathrm{F}$ hitung $=29,6347>$ dari nilai $\mathrm{F}$ crit $=7,0930$ Jadi kuat tekan beton butiran pasir zone I tidak sama dengan beton butiran pasir zone III.

Berdasarkan output tabel 3 dan 4, Ho ditolak karena $\mathrm{F}$ hitung $=125,65>$ dari nilai $\mathrm{F}$ crit $=7,09$. Jadi kuat tekan beton butiran pasir zone I tidak sama dengan beton butiran pasir zone III.

Berdasarkan output tabel 5 dan 6, bahwa Ho ditolak karena $\mathrm{F}$ hitung = $57,87>$ dari nilai $\mathrm{F}$ crit $=7,09$,Jadi kuat tekan beton butiran pasir zone I tidak sama dengan beton butiran pasir zone III. 
Jurnal APLIKASI

\section{ISSN.1907-753X}

Tabel 1. Uji Statistik Anova Satu Arah Beton Pasir Zone I FAS 0,6 dengan Beton Pasir Zone III FAS 0,6 untuk Anova Single

\begin{tabular}{lllll}
\hline Faktor & $\alpha$ & 0,01 & & \\
\hline Summary & & & & \\
\hline Group & Coun & Sum & Average & Variance \\
\hline Data 1 & 30 & 6966,095 & 232,2032 & 439,8974 \\
\hline Data 2 & 30 & 7983,418 & 266,1139 & 724,2178 \\
\hline
\end{tabular}

Tabel 2. Uji Statistik Anova Satu Arah Beton Pasir Zone I FAS 0,6 dengan Beton Pasir Zone III FAS 0,6 untuk Anova

\begin{tabular}{lllllll}
\hline $\begin{array}{l}\text { Source } \\
\text { variation }\end{array}$ & SS & df & MS & F & P-Value & F-crit \\
\hline $\begin{array}{l}\text { Bedween } \\
\text { Groups }\end{array}$ & 17249,10 & 1 & 17249,10 & 29,635 & 0,000 & 7,093 \\
\hline Within Groups & 33759,34 & 58 & 582,05 & & & \\
\hline Total & 51008,44 & 59 & & & & \\
\hline
\end{tabular}

Tabel 3. Uji Statistik Anova Satu Arah Beton Pasir Zone IFAS 0,5 dengan Beton Pasir

\begin{tabular}{|c|c|c|c|c|}
\hline Faktor & $\alpha$ & 0,01 & & \\
\hline \multicolumn{5}{|c|}{ SUMMARY } \\
\hline Group & Coun & Sum & Average & Variance \\
\hline Data 1 & 30 & 10167,7 & 338,924 & 392,526 \\
\hline Data 2 & 30 & 12314,8 & 410,493 & 830,456 \\
\hline
\end{tabular}

Tabel 4. Uji Statistik Anova Satu Arah Beton Pasir Zone IFAS 0,5 dengan Beton Pasir Zone III FAS 0,5 untuk Anova

\begin{tabular}{lllllll}
\hline Source of variation & SS & df & MS & F & $\begin{array}{l}\text { P- } \\
\text { Value }\end{array}$ & F-crit \\
\hline Bedween Groups & 76831,80 & 1 & 76831,80 & 125,647 & 0,000 & 7,093 \\
\hline Within Groups & 35466,50 & 58 & 611,49 & & & \\
\hline Total & 112298 & 59 & & & & \\
\hline
\end{tabular}

Tabel 5. Anova Satu Arah Beton Pasir Zone I FAS 0,3 dengan Beton Pasir Zone III FAS 0,3 untuk Anova Sigle

\begin{tabular}{lllll}
\hline Faktor & $\alpha$ & 0,01 & & \\
\hline SUMMARY & & & & \\
\hline Group & Coun & Sum & Average & Variance \\
\hline Data 1 & 30 & 19115,21 & 637,174 & 896,091 \\
\hline Data 2 & 30 & 17159,81 & 571,993 & 1306,401 \\
\hline
\end{tabular}


Tabel 6. Anova Satu Arah Beton Pasir Zone I FAS 0,3 dengan Beton Pasir Zone III FAS 0,3 untuk Anova

\begin{tabular}{lllllll}
\hline Source of variation & SS & df & MS & F & P-Value & F-crit \\
\hline Bedween Groups & 63726,03 & 1 & 63726,030 & 57,867 & 0,000 & 7,093 \\
\hline Within Groups & 63872,25 & 58 & 1101,246 & & & \\
\hline Total & 127598,3 & 59 & & & & \\
\hline
\end{tabular}

\section{Simpulan}

Dari penelitian dan analisis sesuai dengan berbagai pengujian yang telah dilakukan, mulai dari pengujian bahanbahan penunjang dan pengadukan campuran material beton yang kemudian diperoleh nilai kuat optimum beton. Maka, dapat ditarik kesimpulan sebagai berikut:

1. Dari hasil pengujian kuat tekan pada umur 28 hari yang telah dilakukan, pencampuran butiran pasir zone I dan zone III yang menggunakan faktor air semen (FAS) 0,6 belum memenuhi kuat tekan rencana sebesar $300 \mathrm{~kg} / \mathrm{cm}^{2}$. Sedangkan campuran butiran pasir zone I pada FAS 0,5 kuat tekan umur 28 hari sebesar $402,57 \mathrm{~kg} / \mathrm{cm}^{2}$, pada zone III sebesar $351,56 \mathrm{~kg} / \mathrm{cm}^{2}$, memenuhi syarat kuat tekan beton rencana sebesar $300 \mathrm{~kg} / \mathrm{cm}^{2}$. Pada campuran butiran pasir zone I pada FAS 0,3 kuat tekan umur 28 hari sebesar $560,48 \mathrm{~kg} / \mathrm{cm}^{2}$, dan pada zone III sebesar $663,83 \mathrm{~kg} / \mathrm{cm}^{2}$, sehingga FAS 0,3 zone I dan zone III telah memenuhi syarat kuat tekan beton rencana sebesar $300 \mathrm{~kg} / \mathrm{cm}^{2}$.

2. Berdasarkan dari uji anova satu arah pada pasir zone I dan zone III Fhitung lebih besar dari Fcritis sehingga Ho di tolak jadi kuat tekan beton dengan pasir zone I tidak sama dengan beton pasir zone III.

\section{Daftar Pustaka}

Subakti, Aman, (1995), Teknologi Beton Dalam Praktek, Surabaya: ITS.

Murdock, L.J., Stephanus Hindarko, (1986), Bahan dan Praktek Beton, edisi ke -empat. Jakarta: Erlangga.

Mulyono, (2004), Teknologi Beton, Yogyakarta: Penerbit Andi.

Standar Industri Indonesia (SII) 005280, Mutu dan Cara Uji Agregat Beton, Jakarta: Departemen Perindustrian.

Standar Industri Indonesia (SII) 028780, Mutu dan Cara Uji Pasir Standard, Jakarta: Departemen Perindustrian.

Standar Nasional Indonesia (SNI) 001377, Mutu dan Lama Uji Semen Portland, Jakarta: Departemen Perindustrian.

Standar Nasional Indonesia (SNI) - 03 -2847-2002, Tata Cara Perhitungan Struktur Beton Untuk Bangunan Gedung, Jakarta: Departemen Perindustrian.

Wangsadinata, Wiratman, dkk., (1979), Peraturan Beton Bertulang Indonesia. 